\title{
Antioxidant potential of Emblica officinalis (amla) aqueous extract delays cataractogenesis in hyperglycemic goat lenses
}

\author{
A.M Hajarnavis ${ }^{1}$, P.M Bulakh ${ }^{2}$ \\ Department of Biochemistry, Bharati Vidyapeeth Deemed University Medical College, Pune, India.
}

\begin{abstract}
Aim: To study the antioxidant role of Emblica officinalis aqueous extract in delaying cataractogenesis in hyperglycemic goat lenses. Study design: Experimental study. Place and Duration of study: Department of Biochemistry, Bharati Vidyapeeth Deemed University Medical College, Pune, India, between February 2012 to June 2012. Methodology: Dried powder of Emblica officinalis fruit pericarp was obtained and crude water extract was prepared. Fresh goat lenses were removed from the eyeballs and divided into 3 groups as follows: Group I - Normal lenses, incubated in Tissue Culture medium 199 (TC199), Group II \& IIIExperimental Cataract lenses incubated with TC $199+110 \mathrm{mM}$ Dextrose solution and TC $199+110 \mathrm{mM}$ Dextrose solution $+0.25 \%$ E.officinalis aqueous extract respectively. After 72 hours of incubation, lenses were homogenized in $0.1 M$ sodium phosphate buffer, $\mathrm{pH} 7.4$ and the supernatant was used for biochemical analysis. Effect of the extract on lens total soluble proteins, TBARS and antioxidant enzymes superoxide dismutase, glutathione peroxidase and glutathione reductase was statistically analyzed. Results: The lens total soluble proteins were maintained, TBARS were reduced and there was a significant rise in the activity of antioxidant enzymes SOD, glutathione peroxidase and glutathione reductase in the lenses incubated with the E.officinalis extract as compared to hyperglycemic lenses. Conclusion: The study highlights the antioxidant nature of E.officinalis which may play an important role in the prevention of hyperglycemia induced cataract.
\end{abstract}

Keywords: anticataract, antioxidant, E.officinalis, hyperglycemia, oxidative stress.

\section{Introduction:}

Cataract formation is a common complication of Diabetes mellitus. The risk of cataract is known to increase with the increase in the duration and severity of diabetes ${ }^{[1]}$. The only means of sight restoration for cataract patients is cataract surgery, which is expensive and could result in surgical complications, mainly in diabetics. It is well documented that oxidative stress plays an important role in the progression of diabetes and its complications ${ }^{[2],[3]}$. The ocular tissue, mainly lens, is highly susceptible to damage from free radicals ${ }^{[4]]}$ Lens proteins are long lived and thus highly prone to oxidative damage. Moreover, mature lens fibers have limited capacity to repair or regenerate these proteins ${ }^{[5],[6]}$.

The lens has its own supply of antioxidants, both enzymatic and non-enzymatic, which combat the oxidative stress. These cellular defenses are however greatly impaired during hyperglycemia. It has been reported that both antioxidant nutrients and antioxidant phytochemicals can give help in alleviating diabetes and diabetic complications ${ }^{[7]}$.

Since ancient times many plants are used in Ayurvedic medicine for the treatment of diabetes and its complications. Great effort is now being taken to understand the role of medicinal plants in the treatment and management of these diseases. Herbal preparations containing Emblica officinalis (Amla) have been used in Ayurveda for the treatment of diabetes and also various ocular diseases. This study was undertaken to evaluate the anticataract role of Emblica officinalis (amla) in experimental diabetic cataract.

The anticataract effect of Emblica officinalis (amla) was studied on goat lenses with reference to its ability to preserve lens proteins and its antioxidant property.

\subsection{Preparation of E.Officinalis aqueous extract:}

\section{Materials and Methods:}

Dried powder of Emblica officinalis fruit pericarp was obtained from 'Manakarnika Pharmacy, Pune'. Crude water extract was prepared as mentioned in the Ayurved Pharmacopoea of India (part I, volume 8).

\subsection{Experimental design:}

Fresh goat eyeballs were obtained from the slaughter house and transported to the laboratory in an icebox. Lenses were removed from the eyeballs by intracapsular lens extraction method and divided into 3 groups as follows: Group I - Normal lenses (n=30),incubated in Tissue Culture medium 199 (TC199), Group II \& IIIExperimental Cataract lenses incubated with TC $199+110 \mathrm{mM}$ Dextrose solution and TC $199+110 \mathrm{mM}$ Dextrose solution $+0.25 \%$ E.officinalis aqueous extract respectively. 
Lenses were incubated for 72 hours after which they were homogenized in $0.1 \mathrm{M}$ sodium phosphate buffer, $\mathrm{pH} 7.4$ and $\mathrm{w} / \mathrm{v}$ was adjusted to $10 \mathrm{gm} \%$. The homogenate was centrifuged at $10,000 \mathrm{Xg}$ for 30 minutes at $-4^{\circ} \mathrm{C}$ and the supernatant was used for biochemical analysis.

\subsection{Biochemical estimations:}

The Total soluble lens proteins were estimated by Lowry's method, MDA (malondialdehyde) as an index of lipid peroxidation was quantified as thiobarbituric acid reacting substances (TBARS) by method of Kei Satoh. Activity of enzyme superoxide dismutase was measured spectrophotometrically by monitoring the rate of pyrogallol reduction ${ }^{[8]}$. Randox kits were used for the estimation of glutathione peroxidase using cumene hydroperoxide and GSH as substrate ${ }^{[9]}$ and for glutathione reductase which was assayed by measuring the decrease in absorbance at $340 \mathrm{~nm}$ due to oxidation of NADPH to NADP during conversion of GSSG to GSH [10].

2.4. Statistical Analysis: Values were expressed as mean \pm standard deviation (SD). Statistical comparison of data was done by unpaired students't-test.

\section{Observation and Results:}

3.1 Lens morphological changes: Lenses in Group I (Normal lenses) remained clear and transparent when incubated in tissue culture medium for 72 hours. On the other hand lenses in group II (Dextrose +TC199) developed mature cataract and osmotic swelling was observed whereas in group III (dextrose + TC $199+$ E.officinalis aq extract) the lens transparency was found to be maintained. [Fig. 1]

3.2 Lens Total soluble proteins: The total soluble proteins in the lenses incubated in glucose were found to be significantly decreased $(255 \pm 62.46 \mathrm{mg} / \mathrm{lens})$ as compared to normal lenses $(344 \pm 62.56 \mathrm{mg} / \mathrm{lens})$ while in case of lenses incubated with glucose in presence of E.officinalis extract there was a considerable maintenance of the lens proteins $(299.6 \pm 70.1 \mathrm{mg} / \mathrm{lens})$. This maintenance was statistically significant ( $\mathrm{p}<$ 0.01). [Table-1]

3.3 MDA as an index of lipid peroxidation: was found to be greatly increased in glucose induced cataract lenses $(13.45 \pm 3.0 \mathrm{n}$ moles/gm lens) as compared to normal lenses $(9.56 \pm 3.43 \mathrm{n}$ moles/gm lens). The increase was statistically highly significant. In the lenses incubated with the aqueous extract, there was a significant reduction in the MDA levels $(10.16 \pm 3.12 \mathrm{n}$ moles/gm lens, $)$ as compared to the glucose induced cataract group. [Table.1]

3.4 Antioxidant Enzymes: The specific activity of enzyme superoxide dismutase was significantly decreased $(0.30 \pm 0.15$ units $/ \mathrm{mg}$ lens $)$ in the glucose induced cataract lenses as compared to normal lenses $(0.41 \pm 0.14$ units $/ \mathrm{mg}$ lens $)$. In the lenses incubated with E.officinalis extract there was a marked elevation in the SOD activity ( $0.44 \pm 0.16$ units $/ \mathrm{mg}$ lens) beyond that observed in normal lenses. This increase was statistically highly significant. [Table-2]

The glutathione peroxidase activity was significantly lowered in the group II lenses $(29.71 \pm 13.92$ units $/ \mathrm{mg}$ lens) as compared to the activity in normal lenses $(36.16 \pm 9.90$ units $/ \mathrm{mg}$ lens) and though there was an increase in the GPx activity $(32.80 \pm 6.65$ units/mg lens $)$ in the lenses incubated with the extract, the increase was not statistically significant.[Table-2]

Glutathione reductase was found to be decreased significantly in the glucose induced cataract lenses $(10.49 \pm 2.1$ units/mg lens) as compared to normal lenses $(13.32 \pm 3.55$ units $/ \mathrm{mg}$ lens). There was a highly statistically significant increase in the activity of GRx $(14.31 \pm 4.30$ units/mg lens) in the lenses incubated with E.officinalis extract.[Table-2]

\section{Discussion:}

Cataract formation is a common complication of diabetes mellitus. It is widely accepted that hyperglycemia induces oxidative stress and osmotic imbalance in the lens, eventually leading to cataract formation. Surgical removal of the cataractous lens is the only means of sight restoration in cataract patients. In the recent years, various dietary agents and plant sources are being studied for their role as antioxidants in the prevention of various diseases including diabetes and cataract ${ }^{[11],[12],[13]}$. Researchers have reported that important phytochemicals from plants possibly prevent both age related and diabetic cataract as they are capable of affecting multiple factors responsible for ocular diseases impairing vision.

Emblica officinalis (amla) is a rich source of tannoids, vitamin $\mathrm{C}$ and other phytochemicals known to act as antioxidants. E.officinalis has been used in Ayurveda since ancient times in the treatment of diabetes and 
a number of ocular diseases. In the present study, the ability of E.officinalis to protect the lens against hyperglycemia induced oxidative stress was evaluated.

Hyperglycemia causes chronic irreversible changes in the long lived molecules like crystallins in eye lens. The advanced glycation end products formed are responsible for the protein crosslink formation resulting in loss of soluble proteins in lens ${ }^{[14]}$. Progressive accumulation of AGE's in the lens contributes to accelerated cataractogenesis ${ }^{[15]}$. In this study the lenses incubated with E.officinalis aqueous extract showed a considerable preservation in their total soluble protein content despite of the presence of hyperglycemia.This finding is in confirmation with earlier studies which suggest that phytochemicals of E.officinalis like tannoids, $\beta$-Glucogallin act as inhibitors of enzyme aldose reductase and thereby prevent sorbitol accumulation and hyperglycemia induced lens protein aggregation and insolubilization ${ }^{[16],[17],[18]}$.

The role of E.officinalis as an antioxidant was also observed in this study by noting its effect on lipid peroxidation and antioxidant enzymes SOD, glutathione peroxidase and glutathione reductase. The lipid peroxidation in terms of TBARS was greatly reduced in lenses incubated with the aqueous extract. E.officinalis has been shown to be a potent scavenger of a variety of free radicals like hydroxyl, superoxide, $\mathrm{H}_{2} \mathrm{O}_{2}$ and various others by virtue of its reducing property ${ }^{[19]}$ attributed to the different flavonoids, phenols and ascorbic acid present in this fruit. The hydrolyzable tannins present in amla are also reported to have ascorbic acid like action ${ }^{[20]}$ further contributing to its antioxidant effect.

The antioxidant enzymes SOD, glutathione peroxidase and glutathione reductase were significantly lowered in the glucose induced cataract lenses as a result of the hyperglycemia induced severe oxidative insult. On incubation with amla extract the lenses showed a considerable increase in the activity of all these enzymes despite the presence of hyperglycemia. The utilization of SOD to dismutate superoxide radical to $\mathrm{O}_{2}$ and $\mathrm{H}_{2} \mathrm{O}_{2}$ is probably prohibited by the phytochemicals present in the aqueous extract as they themselves quench the singlet oxygen.

Glutathione peroxidase is an important enzyme in the lens preventing lipid peroxidation with the help of reduced glutathione. Glutathione reductase further regenerates GSH which is also required to maintain the sulphydryl groups of lens proteins and variety of other cellular mechanisms. As discussed earlier, the free radical scavenging action of the amla extract reduces the $\mathrm{H}_{2} \mathrm{O}_{2}$ and other peroxides in the lens, thus conserving glutathione peroxidase and consequently glutathione reductase.

Figure :1

A

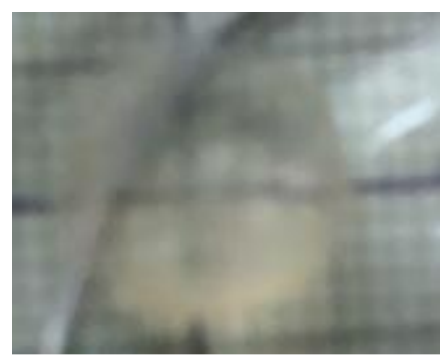

B

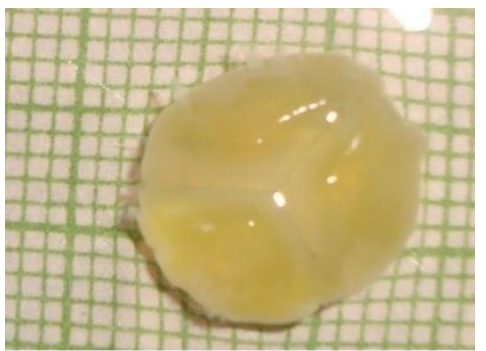

C

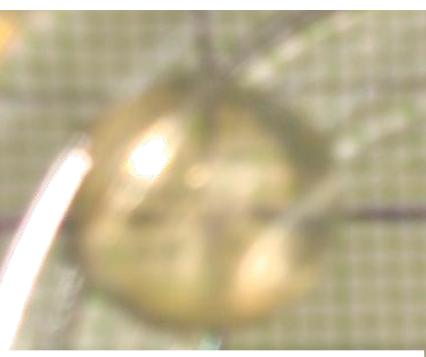

A. Normal lenses incubated in TC199, B. Lenses incubated in TC199 and 110mM dextrose, C. Lenses incubated with TC199 + 110mM dextrose + E.officinalis extract.

Table: 1 Lens Total Soluble Proteins and Malondialdehyde Levels in Normal Dextrose induced cataract and lenses with dextrose and E.officinalis extract.

\begin{tabular}{|l|l|l|l|}
\hline $\begin{array}{l}\text { Sr. } \\
\text { No }\end{array}$ & Group & $\begin{array}{l}\text { Total Soluble Proteins } \\
(\mathrm{mg} / \text { lens }) \\
\text { Mean } \pm \text { SD }\end{array}$ & MDA (n moles/gm lens) \\
\hline 1 & Normal Lenses & $344 \pm 62.56$ & $9.56 \pm 3.43$ \\
\hline 2 & $\begin{array}{l}\text { Dextrose } \\
\text { induced Cataract } \\
\text { lenses }\end{array}$ & $255 \pm 62.46 * *$ \\
\hline 3 & $\begin{array}{l}\text { Dextrose }+ \\
\text { E.officinalis } \\
\text { (Amla) extract }\end{array}$ & $299.6 \pm 70.1 *$ & $13.45 \pm 3.0 * *$ \\
\hline$* * \mathrm{p}<0.001, \quad * 0.16 \pm 3.12 * *$ \\
\hline
\end{tabular}


Table 2: Specific activity of Superoxide Dismutase, Glutathione peroxidase, Glutathione reductase in Normal, Dextrose induced cataract lenses and lenses with dextrose and E.officinalis extract.

\begin{tabular}{|l|l|l|l|l|}
\hline $\begin{array}{l}\text { Sr. } \\
\text { No }\end{array}$ & Group & $\begin{array}{l}\text { Superoxide } \\
\text { dismutase } \\
\text { (units/mg lens) } \\
\text { Mean } \pm \text { SD }\end{array}$ & $\begin{array}{l}\text { Glutathione } \\
\text { peroxidase } \\
\text { (units/mg lens) } \\
\text { Mean } \pm \text { SD }\end{array}$ & $\begin{array}{l}\text { Glutathione } \\
\text { reductase } \\
\text { (units/mg lens) } \\
\text { Mean } \pm \text { SD }\end{array}$ \\
\hline 1 & Normal Lenses & $0.41 \pm 0.14$ & $36.16 \pm 9.90$ & $13.32 \pm 3.55$ \\
\hline 2 & $\begin{array}{l}\text { Dextrose } \\
\text { induced Cataract } \\
\text { lenses }\end{array}$ & $0.30 \pm 0.15 *$ & $29.71 \pm 13.92 *$ & $10.49 \pm 2.11^{* *}$ \\
\hline 3 & $\begin{array}{l}\text { Dextrose }+ \\
\text { E.officinalis } \\
\text { Amla) extract }\end{array}$ & $0.44 \pm 0.16^{* *}$ & $32.80 \pm 6.65$ & $14.31 \pm 4.30^{* *}$ \\
\hline
\end{tabular}

\section{Conclusion:}

The present study indicates that E.officinalis aqueous extract prevents cataract formation in experimental glucose induced cataract. Researchers have already shown the anticataract potential of E.officinalis by virtue of acting as an aldose reductase inhibitor.This study highlights the antioxidant nature of E.officinalis which may also play an important role in the prevention of hyperglycemia induced cataract. Further studies need to be carried out in vivo on animal models and in the form of clinical trials to ascertain the anticataract role of this fruit.

\section{Acknowledgement}

We express our sincere thanks to the Research Cell, Bharati Vidyapeeth Deemed University for funding this study. We also express our gratitude to the Indian Drugs Research Association \& Laboratory, Pune, and Department of Biochemistry, BVDUMC Pune, for their help extended during this study.

\section{References:}

[1] Negahban K, Chern K, Cataracts associated with systemic disorders and syndromes. Curr Opin Ophthalmol. 2002;13:419-422

[2] A Ceriello, Oxidative Stress and glycemic regulation. Metabolism, 2000 Vol. 49(2) : 27-29.

[3] JW Baynes, Role of oxidative stress in development of complications in diabetes. Diabetes 1991, Vol. 40: 405-412.

[4] DL Williams, Oxidation, antioxidants and cataract formation : a literature review, Veterinary Ophthalmology, 2006, Vol. 9 (5): 292298.

[5] Jr Zigler JS, Lens Proteins: Principles and practice of Ophthalmology, Basic Science, (W.B.Saunders Co, Philadelphia), 1994, pp. 97113.

[6] A, Wannemaker CF and Spector, Protein Synthesis in the core of the calf lens. Exp Eye Res, 1968,Vol. 7, p. 623.

[7] Lean ME, Noroozi M, Kelly I, Burns J, Talwar D, Sattar N \& CrozierA. Dietary flavonols protect diabetic human lymphocytes against oxidative damage to DNA. Diabetes 1999.48:176-181.

[8] Marklund and Marklund, Involvement of superoxide anion radical in the autooxidation of pyrogallol and a convinient assay for superoxide dismutase. Eur J Biochem, 1974, Vol. 47, pp. 469-474.

[9] Paglia DE and Valentine WN. J.Lab. Clin Med, Vol. 70, p. 158

[10] RJ Goldberg DM \& Spooner, Methods of Enzymatic analysis( 3rd edition. Vol. 3) pp. 258-265.

[11] Bhimanagouda S et. al, Bioactive Compounds: Historical perspectives, opportunities and challenges. J. Agric. Food Chem, Vol. 5, pp. $8142-8160$.

[12] Majumdar S, Srirangam R, Potential of the bioflavonoids in the prevention \& treatment of ocular disorders. J Pharm Pharmacol, 2010, Vol. 62, pp. 951-965.

[13] Kalt W, Hanneken A, Milbury P, Tremblay F, Recent research on polyphenolics in vision and eye health. J Agric Food Chem, 2010, Vol. 58, pp. 4001-4007.

[14] Brownlee M, Advanced glycation end products in diabetes and ageing. Annual Review of Medicine, 1996, Vol. 46, pp. $223-234$.

[15] Araki N, Ueno N, Chakrabati B, Morino, Y \& Horiuchi S, Immunochemical evidence for the presence of advanced glycation end products in human lens proteins and its positive correlation with aging. Journal of Biological Chemistry, Vol. 267, pp. 1021110214.

[16] P Suryanarayana, Megha Saraswat, J Mark Petrash, G Bhanuprakash Reddy. Emblica officinalis and its enriched tannoids delay streptozotocin induced diabetic cataract in rats. Molecular Vision , 2007;Vol. 13, pp. 1291-1297.

[17] Suryanarayana P, Kumar PA, Saraswat M, Petrash JM, Reddy GB. Inhibition of aldose reductase by tannoid principles of Emblica officinalis:implications for the prevention of sugar cataract. Mol Vis , 2004,Vol. 10: pp. 148-154.

[18] Muthenna Puppala, Jessica Ponder, Palla Suryanarayana, Geereddy Bhanuprakash Reddy, J.Mark Petrash, Daniel V. LaBarbera. The Isolation and Characterization of b-Glucogallin as a Novel Aldose Reductase Inhibitor from Emblica officinalis: PLoS ONE, 2012, Vol. 7(4),www.plosone.org

[19] Bibhabasu Hazra, Rhitajit Sarkar, Santanu Biswas and Nripendranath Mandal. Comparative study of the antioxidant and reactive oxygen species scavenging properties in the extracts of the fruits of Terminalia chebula,Terminalia belerica and Emblica officinalis. BMC Complementary and Alternative Medicine, 2010, Vol. 10, p 20

[20] Pozharitskaya ON, Ivanova SA, Shikov AN. Separation and evaluation of free radical scavenging activity of phenol components of Emblica officinalis extract using HPTLC-DPPH method. J Sep Sci, 2011, Vol. 2(8) pp. 38-42. 